\title{
Estimating Drug Costs: How do Manufacturer Net Prices Compare with Other Common US Price References?
}

\author{
T. Joseph Mattingly II ${ }^{1}$ (i) $\cdot$ Joseph F. Levy $^{1}$ (1) $\cdot$ Julia F. Slejko $^{1}$ (i) $\cdot$ Nneka C. Onwudiwe $^{2} \cdot$ \\ Eleanor \\ M. Perfetto ${ }^{1}$
}

Published online: 12 May 2018

(C) The Author(s) 2018

\begin{abstract}
Background Drug costs are frequently estimated in economic analyses using wholesale acquisition cost (WAC), but what is the best approach to develop these estimates? Pharmaceutical manufacturers recently released transparency reports disclosing net price increases after accounting for rebates and other discounts.

Objective Our objective was to determine whether manufacturer net prices (MNPs) could approximate the discounted prices observed by the U.S. Department of Veterans Affairs (VA).

Methods We compared the annual, average price discounts voluntarily reported by three pharmaceutical manufacturers with the VA price for specific products from each company. The top 10 drugs by total sales reported from company tax filings for 2016 were included. The discount observed by the VA was determined from each drug's list price, reported as WAC, in 2016. Descriptive statistics were calculated for the VA discount observed and a weighted price index was calculated using the lowest price to the VA (Weighted VA Index), which was compared with the manufacturer index.

Results The discounted price as a percentage of the WAC ranged from 9 to $74 \%$. All three indexes estimated by the average discount to the VA were at or below the manufacturer indexes ( 42 vs. $50 \%$ for Eli Lilly, 56 vs. $65 \%$ for Johnson \& Johnson, and 59 vs. 59\% for Merck).
\end{abstract}

T. Joseph Mattingly II

jmattingly@rx.umaryland.edu

1 University of Maryland School of Pharmacy, 20 North Pine Street, N415, Baltimore, MD 21201, USA

2 US Food and Drug Administration, Silver Spring, MD, USA
Conclusions Manufacturer-reported average net prices may provide a close approximation of the average discounted price granted to the VA, suggesting they may be a useful proxy for the true pharmacy benefits manager (PBM) or payer cost. However, individual discounts for products have wide variation, making a standard discount adjustment across multiple products less acceptable.

\section{Key Points for Decision Makers}

Voluntarily-reported manufacturer net prices (MNPs) may provide some insight into true prices observed by pharmacy benefits managers or payers negotiating discounts from the list price for a large portfolio of pharmaceuticals.

An average MNP may not be helpful for researchers interested in drug- or disease-specific price estimates as significant heterogeneity exists across individual products.

\section{Introduction}

Retail prescription drug spending in the US has been estimated at over US $\$ 340$ billion annually, with projected growth to nearly US $\$ 600$ billion by 2025 , accounting for more than $10 \%$ of total healthcare spending in the US $[1,2]$. High costs of new drugs and price increases for existing products have brought criticism and political interest in the drug pricing debate over rising drug prices as 
well as cost effectiveness and affordability [3-6]. Drug price transparency has been argued as a potential solution to improve affordability within the US and abroad as it would improve the negotiating position for purchasers around the world [7]. In response, several states have introduced legislation to address price increases through a variety of mechanisms, including proposals from policymakers allowing Medicare to negotiate drug prices, greater drug price transparency, modifying regulations to speed generic drugs and biosimilars to market, value-based purchasing, reference pricing, reducing drug companies' market exclusivity period, and extending the Medicaid drug price rebate to low-income Medicare Part D enrollees $[8,9]$. High consumer out-of-pocket costs, drug manufacturer shortages, secondary wholesale strategies, and price gouging practices have raised concerns across the US, with rising drug costs offering challenges to patients, policy makers, payers, and providers in terms of treatment decisions [10].

Increased attention to drug pricing, and healthcare spending overall, has led to more emphasis on using economic methods to determine the value of therapies to help inform medical decisions [11]. Approaches to estimating drug costs for economic evaluation can vary, but most costeffectiveness analyses (CEAs) utilize the manufacturer list price to wholesalers or wholesale acquisition cost (WAC) to estimate the drug cost parameter [12]. This is problematic as there are rebates and discounts that are known to be offered to pharmacy benefits managers (PBMs) on behalf of payers in proprietary negotiations. While the dollar amounts negotiated between PBMs and manufacturers are unknown, there is substantial evidence to suggest that amount may vary between PBMs and molecules $[13,14]$. Presumably, market forces impact the ability of different PBMs/payers to negotiate these discounts and rebates, such as market share, patient population, or inclass competition specific to certain drugs.

The International Society for Pharmacoeconomics and Outcomes Research (ISPOR) Drug Cost Task Force report recommends that evaluations from the payer perspective use a drug price adjusted for all rebates, or price concessions from the manufacturer to the payer; however, there is limited guidance or empirical evidence to support how to obtain or estimate the drug price parameter $[15,16]$. Challenges for researchers conducting pharmacoeconomic studies exist for both branded and generic products. Generic or multi-sourced pharmaceuticals may have a wide range of publicly available list prices in Red Book, depending on variables such as manufacturer, package size, or strength, therefore determining the best price source and distribution may be product-specific [17]. Brand or singlesourced products may have only one WAC in Red Book, but this list price does not account for the rebates or discounts previously discussed. In section 8126 (b) of title 38, United States Code describes the brand-name drug discount program in the Federal Supply Schedule (FSS), which includes the Department of Veterans Affairs (VA), Department of Defense, Public Health Service, and Coast Guard (also referred to as the 'Big Four') [18]. By using the pharmaceutical catalog within the VA National Acquisition Center (NAC), researchers have access to both the FSS and Big Four contract prices [19]. Levy et al. provided one potential method to estimate the base-case drug price input, along with upper and lower bounds, based on the publicly available National Average Drug Acquisition Cost (NADAC) and the minimum FSS (the lower of the FSS or Big Four price listed) in the catalog as measures for the drug product of interest [12].

In response to growing concern around the drug price debate, three pharmaceutical manufacturers have released price transparency reports to disclose the net price increases their companies observe after accounting for rebates to PBMs and other discounts. This manufacturer net price (MNP) disclosure may provide researchers with a new approach to estimating drug input parameters, but the methods used to develop are not quite clear and these reports only provide aggregated price increase estimates for the entire drug portfolio for each manufacturer [20-22]. Our primary objective was to evaluate MNPs compared with publicly available prices observed by the US VA. Understanding the magnitude of discounts observed across different pharmaceuticals and payers may help guide researcher selection of price estimates for CEAs and other analyses.

\section{Methods}

\subsection{Inclusion/Exclusion Criteria}

In this study, we identified the top 10 pharmaceutical products by sales (in US dollars) in 2016 for each of the three pharmaceutical manufacturers that voluntarily released drug price transparency reports in 2017, i.e. Eli Lilly, Johnson \& Johnson, and Merck [20-22]. Pharmaceutical product sales (in US dollars) for 2016 were identified in each company's publicly available annual $10-\mathrm{K}$ report. Since each company grouped multiple formulations, package sizes, and dosage forms under one financial sales number in the $10-\mathrm{K}$ tax report, we selected a commonly used National Drug Code (NDC) based on the primary author's pharmacy operations and procurement experience. 


\subsection{Data}

Once a single NDC was determined from each company's top 10 drugs, it was used to identify the WAC in Red Book, the FSS, and the lowest price reported by the VA for each product using the NAC pharmaceutical catalog [19, 23]. The MNP was estimated from individual drug price transparency reports published by each manufacturer [20-22]. According to the repots, all three companyspecific MNPs were calculated internally based on a WAC minus rebates and discounts calculation that was weighted across each company's portfolio. The details of each weighting method or specific approach was not disclosed. The period of 2016 was selected based on the availability of transparency report data across all three manufacturers.

\subsection{Analysis}

All companies identified either the annual average discount from the list price or described the net price weighted across their entire portfolio (Manufacturer Index). This Manufacturer Index reported by each company ( $j$ ) was applied to the individual $(i)$ unit WAC price reported in Red Book to estimate an MNP for each NDC and for each year on a per unit basis (Eq. 1). The WAC price per unit was based on package size and number of individual units of use (tablets, capsules, syringes, milliliters, etc.).

$\mathrm{MNP}_{i}=\mathrm{WAC}_{i} \times(\text { Manufacturer Index })_{j}$.

The estimated MNP for each product was compared with the lowest price available in the NAC pharmaceutical catalog for each year, defined here as the VA price. Additionally, a VA price index (VA Index) was determined from the VA price as a percentage of WAC for each NDC, and a final weighted VA price index (Weighted VA Index) was determined based on US dollar sales in 2016 for each company. Rank order expected was determined assuming that the lowest price available to the VA was the lowest price for any purchaser; we assumed that the MNP would always be higher and calculated the proportion of drugs where the VA price was not lower than the MNP. This allowed us to address two research questions: (1) to what extent are company-generated transparency reports useful to better approximate the acquisition cost of individual drugs compared with the WAC or VA price; and (2) to what extent is the reported MNP a reasonable proxy for a payer cost net of rebates and discounts.

\section{Results}

Thirty brand-name drug products were included in the analysis, with sales in 2016 ranging from $\$ 0.5$ billion to $\$ 6$ billion (Table 1). The WAC price, FSS price, and VA price for each product are listed in Table 1. The discounted price as a percentage of the WAC price ranged from 9 to $74 \%$. In terms of individual product comparison, 63\% (19/ 30) of the sample had a larger VA discount than MNPs (Table 2). This varied by manufacturer as $90 \%(9 / 10)$ of the Johnson \& Johnson products, $60 \%$ (6/10) of the Eli Lilly products, and $40 \%$ (4/10) of the Merck products provided larger discounts to the VA. All three indexes estimated by the average discount to the VA were at or below the manufacturer indexes (42 vs. 50\% for Eli Lilly, 56 vs. $65 \%$ for Johnson \& Johnson, and 59 vs. $59 \%$ for Merck).

\section{Discussion}

When choosing branded drug price input parameters for the US payer perspective, CEA researchers have multiple publicly available options to consider. In 2010, recommendations from the ISPOR Drug Cost Task Force report suggested a base-case rebate of $15 \%$, with a range from 5 to $25 \%$ for a drug placed on the second-tier of a managed care formulary [16]. The Task Force also eluded to differences in the degree of in-class drug competition that may also influence the size of rebate provided by the manufacturer for formulary placement [16]. The manufacturer drug price transparency reports released over the last year indicate that the average drug price discount across a portfolio of drugs may be substantially higher [20-22]. Our analysis of the publicly available discounts to the VA supports the claim that true payer costs for the drug, net of rebates and discounts, may be much lower. In the case of Eli Lilly's Humulin ${ }^{\circledR}$ insulin product that brought in $\$ 1.4$ billion in sales in 2016, the lowest price available to the VA was discounted $91 \%$ from WAC. The company's fast-acting Humalog ${ }^{\circledR}$ insulin product observed an $81 \%$ price rebate/discount from WAC, supporting the Task Force's suggestion of in-class competition as Eli Lilly must compete with Novo Nordisk's line of insulin products that are interchanged frequently in practice. Velcade ${ }^{\circledR}$, Keytruda $^{\circledR}$, Cyramza $^{\circledR}$, and Alimta ${ }^{\circledR}$ demonstrated the smallest discounts from WAC to the VA (ranging from 26 to $30 \%$ ), which suggests economic modelers should consider a lower base-case rebate in oncology that may be more in line with the $5-25 \%$ suggestion from the Task Force. One possibility for future researchers would be to estimate the Weighted VA Index within various therapeutic 
Table 1 Comparison of WAC, FSS, and VA prices for the top 10 drugs identified through company annual tax filings and drug costs included in analysis, in 2016 US dollars

\begin{tabular}{|c|c|c|c|c|}
\hline Brand name (generic name) & Sales $^{\mathrm{a}}$ & $\mathrm{WAC}^{\mathrm{b}}$ & $\mathrm{FSS}^{\mathrm{b}}$ & VA price ${ }^{\mathrm{b}}$ \\
\hline \multicolumn{5}{|l|}{ Eli Lilly } \\
\hline Humalog (insulin lispro) & 2.8 & 25.33 & 4.72 & 4.72 \\
\hline Cialis (tadalafil) & 2.5 & 54.76 & 32.81 & 26.02 \\
\hline Alimta (pemetrexed) & 2.3 & 3203.10 & 3033.48 & 2238.28 \\
\hline Forteo (teriparatide) & 1.5 & 1125.46 & 477.39 & 477.39 \\
\hline Humulin (insulin human regular) & 1.4 & 13.71 & 1.25 & 1.25 \\
\hline Cymbalta (duloxetine) & 0.9 & 10.47 & 7.27 & 5.44 \\
\hline Trulicity (dulaglutide) & 0.9 & 310.96 & 124.49 & 93.17 \\
\hline Strattera (atomoxetine) & 0.9 & 14.32 & 6.89 & 6.34 \\
\hline Zyprexa (olanzapine) & 0.7 & 26.55 & 13.80 & 13.80 \\
\hline Erbitux (cetuximab) & 0.7 & 11.47 & 10.81 & 7.97 \\
\hline \multicolumn{5}{|l|}{ Johnson \& Johnson } \\
\hline Remicade (infliximab) & 6.0 & 1110.60 & 656.46 & 582.10 \\
\hline Stelara (ustekinumab) & 3.2 & 17570.10 & 9693.19 & 9693.19 \\
\hline Invega (paliperidone) & 2.2 & 1456.67 & 1198.75 & 932.18 \\
\hline Zytiga (abiraterone) & 2.2 & 71.33 & 45.24 & 45.24 \\
\hline Xarelto (rivaroxaban) & 2.2 & 11.91 & 7.42 & 7.15 \\
\hline Prezista (darunavir) & 1.8 & 22.48 & 20.74 & 14.51 \\
\hline Simponi (golimumab) & 1.7 & 7561.99 & 1716.81 & 1761.81 \\
\hline Invokana (canagliflozin) & 1.4 & 12.95 & 8.91 & 7.78 \\
\hline Imbruvica (ibrutinib) & 1.3 & 123.37 & 69.56 & 69.56 \\
\hline Velcade (bortezomib) & 1.2 & 1612.62 & 1498.68 & 1200.70 \\
\hline \multicolumn{5}{|l|}{ Merck } \\
\hline Januvia (sitagliptin) & 3.9 & 12.70 & 9.01 & 7.98 \\
\hline Zetia (ezetimibe) & 2.5 & 10.46 & 8.65 & 4.92 \\
\hline Janumet XR (metformin/sitagliptin) & 2.2 & 6.35 & 5.36 & 4.00 \\
\hline Gardasil (human papillomavirus vaccine) & 2.1 & 1601.68 & 1409.88 & 961.29 \\
\hline ProQuad (MMRV vaccine) & 1.6 & 1906.18 & 1613.73 & 1067.62 \\
\hline Keytruda (pembrolizumab) & 1.4 & 1111.63 & 1100.26 & 813.49 \\
\hline Isentress (raltegravir) & 1.4 & 23.16 & 19.45 & 13.92 \\
\hline Remicade (infliximab) & 1.3 & 1110.60 & 656.46 & 582.10 \\
\hline Vytorin (ezetimibe/simvastatin) & 1.6 & 10.36 & 8.57 & 4.88 \\
\hline Cubicin (daptomycin) & 1.1 & 445.49 & 317.44 & 289.94 \\
\hline
\end{tabular}

$W A C$ wholesale acquisition cost, FSS Federal Supply Schedule, VA Veterans Affairs, $X R$ extended release, $M M V R$ measles, mumps, rubella, and varicella

${ }^{\mathrm{a}}$ In billions

${ }^{\mathrm{b}}$ Per unit cost in US dollars categories to determine whether this could provide a more useful discount for economic models.

Levy et al. suggested using the NADAC and VA FSS as upper and lower bounds for US drug price parameters in economic evaluations, with the midpoint between those two as the base case [12]. The authors stated the midpoint between NADAC and VA FSS was selected for the base case for simplicity and lack of another obvious measure, thus making the argument for more transparency around rebates and net prices [12]. The present study supports the VA price for a lower-bound estimate since the manufacturer index from three large drug manufacturers was slightly higher than the Weighted VA Index. The MNP represents an aggregated price received potentially inclusive of all discounts and rebates secured by PBMs on behalf of payers, but the payer may still pay a higher price based on the PBM contract.

One unexpected finding was that for one of the manufacturers, the VA price was equal to the reported manufacturer index in 2016. An explanation for this is that the MNP includes drug costs paid by non-insurance company payers such as hospitals. Certain hospitals receive drug 
Table 2 Lowest publicly available price through the VA compared with the MNP

\begin{tabular}{|c|c|c|c|c|c|c|}
\hline $\begin{array}{l}\text { Brand name, by } \\
\text { manufacturer }\end{array}$ & $\begin{array}{l}\text { VA price }{ }^{\mathrm{a}} \text { (unit } \\
\text { cost) }\end{array}$ & $\begin{array}{l}\mathrm{MNP}^{\mathrm{a}} \text { (unit } \\
\text { cost) }\end{array}$ & $\begin{array}{l}\text { Rank order } \\
\text { expected }^{\mathrm{b}}\end{array}$ & $\begin{array}{l}\text { VA index }{ }^{\mathrm{c}}(\mathrm{VA} \\
\text { price })\end{array}$ & $\begin{array}{l}\text { Manufacturer index } \\
\text { (reported) }\end{array}$ & $\begin{array}{l}\text { Weighted VA index } \\
\text { (VA price) }\end{array}$ \\
\hline \multicolumn{7}{|l|}{ Eli Lilly } \\
\hline Humalog & 4.72 & 12.66 & Yes & 19 & 50 & 42 \\
\hline Cialis & 26.02 & 27.38 & Yes & 48 & & \\
\hline Alimta & 2238.28 & 1601.55 & No & 70 & & \\
\hline Forteo & 477.39 & 562.73 & Yes & 42 & & \\
\hline Humulin & 1.25 & 6.86 & Yes & 9 & & \\
\hline Cymbalta & 5.44 & 5.23 & No & 52 & & \\
\hline Trulicity & 93.17 & 155.48 & Yes & 30 & & \\
\hline Strattera & 6.34 & 7.16 & Yes & 44 & & \\
\hline Zyprexa & 13.80 & 13.28 & No & 52 & & \\
\hline Erbitux & 7.97 & 5.74 & No & 69 & & \\
\hline \multicolumn{7}{|c|}{ Johnson \& Johnson } \\
\hline Remicade & 582.10 & 719.67 & Yes & 52 & 65 & 56 \\
\hline Stelara & 9693.19 & 11385.42 & Yes & 55 & & \\
\hline Invega & 932.18 & 943.92 & Yes & 64 & & \\
\hline Zytiga & 45.24 & 46.22 & Yes & 63 & & \\
\hline Xarelto & 7.15 & 7.72 & Yes & 60 & & \\
\hline Prezista & 14.51 & 14.57 & Yes & 65 & & \\
\hline Simponi & 1761.81 & 4900.17 & Yes & 23 & & \\
\hline Invokana & 7.78 & 8.39 & Yes & 60 & & \\
\hline Imbruvica & 69.56 & 79.94 & Yes & 56 & & \\
\hline Velcade & 1200.70 & 1044.98 & No & 74 & & \\
\hline \multicolumn{7}{|l|}{ Merck } \\
\hline Januvia & 7.98 & 7.51 & No & 63 & 59 & 59 \\
\hline Zetia & 4.92 & 6.18 & Yes & 47 & & \\
\hline Janumet XR & 4.00 & 3.75 & No & 63 & & \\
\hline Gardasil & 961.29 & 946.59 & No & 60 & & \\
\hline ProQuad & 1067.62 & 1126.55 & Yes & 56 & & \\
\hline Keytruda & 813.49 & 656.97 & No & 73 & & \\
\hline Isentress & 13.92 & 13.69 & No & 60 & & \\
\hline Remicade & 582.10 & 656.36 & Yes & 52 & & \\
\hline Vytorin & 4.88 & 6.12 & Yes & 47 & & \\
\hline Cubicin & 289.94 & 263.28 & No & 65 & & \\
\hline
\end{tabular}

$V A$ Veterans Affairs, $M N P$ manufacturer net price, $X R$ extended release

${ }^{\mathrm{a}}$ In US dollars

${ }^{b}$ Rank order expected was 'yes' if the VA price for the individual drug was lower than the MNP

${ }^{\mathrm{c}}$ Index values are reported as percentages

prices under the 340B program, which provides substantial discounts, far greater than those received by most favored private payers (and the VA) [24]. This could partially explain why the rank order for this manufacturer, as well as the rank orders of many of the individual products, was not as expected. Unfortunately, data on the per unit costs granted under the $340 \mathrm{~B}$ program, as well as the proportion of sales that it represents, are not publicly available. The current aggregated net prices in the transparency reports do not state whether or not these $340 \mathrm{~B}$ price concessions are included in the methods used to calculate MNPs [20-22].

The current political environment around drug pricing in the US has led to more calls for transparency regarding both manufacturers and health insurers $[25,26]$. Price transparency throughout the supply chain for pharmaceuticals would add to the information available for decision 
making [25]. While publication of average net prices for an entire company's portfolio may offer some insight into the magnitude of rebates, applying the average portfolio discount to the drug of interest in a CEA could be less reliable than a NADAC-VA price approach. For researchers interested in the cost effectiveness of a class of drugs in the US population, the MNP may be a better estimate for private payers as one would expect the VA price to underestimate the drug cost.

To our knowledge, this analysis is the first attempt to test the overall usefulness of the recently published transparency reports for estimating drug costs. This study only focuses on the drug manufacturers who reported drug prices as an average net price after all rebates and discounts, making it difficult to extrapolate to all brand manufacturers due to a self-selection bias. Additionally, including only the top 10 drugs by sales may limit the estimate, but, in all three cases, these drugs made up a significant amount of total drug sales in the manufacturer portfolio. For this initial analysis, only one NDC for each drug product was utilized based on expert opinion. Since all 30 drug products were single-source brand-name drugs, several had only one or two NDCs available, and 16 of the 30 had the exact same unit price across all NDCs. Discrepancies across NDCs were typically related to dosage or package size. Future analyses may consider using real-world claims that specify the NDC dispensed to address this potential limitation. The MNP reported may also include the discounts provided to covered entities under the $340 \mathrm{~B}$ drug pricing program, which may be significantly higher than the average discount provided to all payers [24].

\section{Conclusions}

Manufacturer drug price transparency reports appear to be a relatively close approximation of the average discounted price granted to the VA, suggesting they may serve as a proxy for what is being actually paid by a PBM or thirdparty payer. However, individual discounts for products have substantial variation, therefore using a standard discount reported from a company's full portfolio is probably not acceptable.

Author Contributions TJM and JFL collected and analyzed the data, and participated in manuscript writing and review. JFS, NCO, and EMP advised on the methods, and participated in manuscript review and revisions.

\section{Compliance with Ethical Standards}

Conflict of interest $\mathrm{T}$ Joseph Mattingly II has received funding from ALK, Inc. and Bristol Myers Squibb for research unrelated to this study, and consulting fees for advisory boards from Summit Therapeutics and Paratek Pharmaceuticals, also unrelated to this study. Joseph F. Levy receives postdoctoral fellowship support from Merck \& Co. Inc. Julia F. Slejko has received funding for research from Takeda Pharmaceuticals USA, Inc., Novartis Pharmaceuticals Corporation, and PhRMA Foundation, unrelated to this study, as well as consulting fees from Pfizer, Inc., also for work unrelated to this study. Nneka C. Onwudiwe has no conflicts of interest, however wishes to add the following statement: 'This article reflects the views of the author and should not be construed to represent the FDA's views or policies'. Eleanor M. Perfetto has no conflicts of interest to disclose.

Funding All authors declare that they received no financial support for this study.

Data availability statement The model developed within this study is available from the corresponding author upon request. All data inputs are described in the paper.

Open Access This article is distributed under the terms of the Creative Commons Attribution-NonCommercial 4.0 International License (http://creativecommons.org/licenses/by-nc/4.0/), which permits any noncommercial use, distribution, and reproduction in any medium, provided you give appropriate credit to the original author(s) and the source, provide a link to the Creative Commons license, and indicate if changes were made.

\section{References}

1. Martin AB, Hartman M, Washington B, Catlin A, National Health Expenditure Accounts Team. National Health Spending: faster growth in 2015, as coverage expands and utilization increases. Health Aff. 2017;2017(36):166-76.

2. Keehan SP, Stone DA, Poisal JA, Cuckler GA, Sisko AM, Smith SD, et al. National health expenditure projections, 2016-25: price increases, aging push sector to $20 \%$ of economy. Health Aff. 2017;36:553-63.

3. Ward JW, Mermin JH. Simple, effective, but out of reach? Public health implications of HCV drugs. $\mathrm{N}$ Engl $\mathrm{J}$ Med. 2015;373:2678-80.

4. Hirsch BR, Balu S, Schulman KA. The impact of specialty pharmaceuticals as drivers of health care costs. Health Aff. 2014;33:1714-20.

5. Chhatwal J, Kanwal F, Roberts MSMS, Dunn MAMA. Costeffectiveness and budget impact of hepatitis $\mathrm{C}$ virus treatment with sofosbuvir and ledipasvir in the United States. Ann Intern Med. 2015;162:397-406.

6. Kantarjian H, Rajkumar SV. Why are cancer drugs so expensive in the United States, and what are the solutions? Mayo Clin Proc. 2015;90:500-4.

7. Vogler S, Paterson KR. can price transparency contribute to more affordable patient access to medicines? Pharmacoecon Open. 2017;1:145-7.

8. Ramsey L. "More is possible": a bunch of states are taking on high drug prices, and it could start hitting drugmaker profits. 2017. http://www.businessinsider.com/states-with-drug-pricingtransparency-bills-2017-6/\#maryland-is-tackling-generic-drugprice-hikes-1. Accessed 11 Nov 2017.

9. Cubanski J, Neuman T. Searching for savings in medicare drug price negotiations. San Francisco: Kaiser Family Foundation; 2017.

10. McRae J, Vogenberg FR, Beaty SW, Mearns E, Varga S, Pizzi L. A review of US drug costs relevant to medicare, medicaid, and 
commercial insurers post-affordable care act enactment, 2010-2016. Pharmacoeconomics. 2017;35:215-23.

11. Neumann PJ, Cohen JT. Measuring the value of prescription drugs. N Engl J Med. 2015;373:2595-7.

12. Levy J, Rosenberg M, Vanness D. A transparent and consistent approach to assess US outpatient drug costs for use in cost-effectiveness analyses. Value Health. 2017.https://doi.org/10.1016/ j.jval.2017.06.013.

13. Kirkwood JB. Buyer power and healthcare prices. Wash Law Rev. 2016;91:253-93.

14. Ellison SF, Snyder CM. Countervailing power in wholesale pharmaceuticals. J Ind Econ. 2010;58:32-53.

15. Hay JW, Smeeding J, Carroll NV, Drummond M, Garrison LP, Mansley EC, et al. Good research practices for measuring drug costs in cost effectiveness analyses: issues and recommendations: the ISPOR drug cost task force report-part I. Value Health. 2010;13:3-7.

16. Mansley EC, Carroll NV, Chen KS, Shah ND, Piech CT, Hay JW, Smeeding J. Good research practices for measuring drug costs in cost-effectiveness analyses: a managed care perspective: the ISPOR drug cost task force report-part III. Value Health. 2010;13:14-7.

17. Levy JF, Meek PD, Rosenberg MA. US-based drug cost parameter estimation for economic evaluations. Med Decis Mak. 2015;35(5):622-32.
18. 38 U.S. Code $\S 8126$ - Limitation on prices of drugs procured by Department and certain other Federal agencies.

19. US Department of Veterans Affairs. National Acquisition Center. 2017. https://www.va.gov/nac/. Accessed 30 Sep 2017.

20. Eli Lilly and Company. Lilly 2016 Integrated Summary Report. 2017. https://www.lilly.com/2016-integrated-summary-report. Accessed 17 Sep 2017.

21. Janssen Pharmaceuticals. 2016 Janssen U.S. Transparency Report. 2017. http://www.janssen.com/us/value-and-pricing. Accessed 17 Sep 2017.

22. Merck Sharp \& Dohme Corp. Pricing Action Transparency Report. 2016. http://www.msdresponsibility.com/ethics-transparency/trans parency-disclosures/. Accessed 17 Sep 2017.

23. Redbook Online ${ }^{\mathrm{TM}}$ from Micromedex Solutions ${ }^{\circledR}$. Truven Health Analytics, Ann Arbor (MI). http://micromedex.com/redbook. Accessed 17 Sep 2017.

24. Conti RM, Bach PB. Cost consequences of the 340B drug discount program. JAMA. 2013;309:1995-6.

25. Moon S. Removing the blindfold on medicines pricing. BMJ. 2018;840:k840.

26. Lyles A. Pharmacy benefit management companies: do they create value in the US healthcare system? Pharmacoeconomics. 2017;35:493-500. 